\title{
A Markov switching regime model of the South African business cycle
}

\author{
Elna Moolman
}

\begin{abstract}
Linear models are incapable of capturing business cycle asymmetries. This has recently spurred interest in non-linear models such as the Markov switching regime (MS) technique of modelling business cycles. The MS model can distinguish business cycle recession and expansion phases, and is sufficiently flexible to allow different relationships to apply over these phases. In this study, the South African business cycle is modelled using a MS model. This technique can be used to simultaneously estimate the data generating process of real GDP growth and classify each observation into one of two regimes (i.e. low-growth and highgrowth regimes).
\end{abstract}

Keywords: Markov switching regime model; Business cycle; South Africa

\section{Introduction}

Business cycles often exhibit several common characteristics. One such characteristic is cyclical asymmetry, whereby the economy behaves differently over the expansion and recession phases of the business cycle (see e.g. Kontolemis, 1999). Although a wide variety of linear and non-linear time series techniques have been employed to model various features of the business cycle, linear models are incapable of capturing business cycle asymmetries. Consequently, there has recently been much interest in non-linear specifications of a type that can distinguish business cycle recession and expansion phases and are sufficiently flexible to allow different

relationships to apply over these phases (Simpson et al., 2001). The non-linear business cycle methods employed to capture these observed asymmetries include threshold models, smooth transition autoregressive models (e.g. Terasvirta and Anderson (1992)) and Markov switching regime (MS) models (e.g. Hamilton (1989)).

Hamilton (1989) first introduced the MS model, which is a stochastic regime model, to business cycle modelling. He applied this model to economic growth. The model has been increasingly used to assist in the dating and forecasting of turning points in the business cycle. The model is conceptually appealing, because in that over time the variable of interest, such as some appropriate measure of the business cycle, is regarded as having a certain probability of switching abruptly among a number of regimes. In the case of the business cycle, expansions and contractions might be considered as the two regimes, each with specific characteristics such as a unique mean and variance. In other words, the business cycle switches between a high-growth and a low-growth regime.

These discrete shifts have their own dynamics, specified as a MS process. An attractive 
feature of the model is that no prior information regarding the dates when the economy was in each regime, or the size of the two growth rates is required. This is in contrast with models such as probit and logit models which require and depend heavily upon the exact dates of all the regimes in the history of the series. In the case of the MS model, the probability of being in a particular regime is inferred from the data.

In this study, the South African business cycle will be modelled using a MS model. The purpose of the MS model is twofold. First, it estimates the data generating process (DGP) of the variable under consideration. Second, it can be used to classify each observation into one of two regimes, which can in turn be used to predict turning points in the cycles when a number of observations in one regime are followed by a number of observations in the other regime. In the empirical analysis, the performance of the MS model in each of these two aspects will be compared against other models that have the same purpose. Specifically, the performance of the MS model in terms of modelling the growth rate will be compared against an autoregressive model. The accuracy of the turning points predicted by the MS model will be compared against the outcomes of a logit model.

In this type of study, where turning points in the business cycle are modelled, it has become increasingly popular to use the yield spread as the explanatory or information variable (see e.g. Estrella and Hardouvelis (1991), Bernard and Gerlach (1996) and Estrella and Mishkin (1998)). In this study, the yield spread will be used as explanatory or information variable in both the MS model and the logit model.

The outline of the paper is as follows: the next section will summarize the theory of the lagged relationship between the yield spread and the business cycle. In Section 3, the MS and logit techniques are explained. Section 4 provides an overview of the empirical literature of modelling the business cycle using the MS technique. It also provides empirical models of the relationship between the yield spread and the business cycle.

\section{The business cycle and the yield spread}

There are two explanations for the relationship between the business cycle and the term structure of interest rates (the so-called 'yield spread' between similar long-term and shortterm interest rates). For the first explanation, assume that the economy is currently enjoying high growth, so that there is a general agreement among investors that the economy is heading for a slow-down or recession in the future. Investors want to hedge against recession and therefore purchase financial instruments (e.g. long-term bonds) that will deliver pay-offs during the economic slowdown. The increased demand for long-term bonds causes an increase in the price of long-term bonds, in other words, a decrease in the yield on long-term bonds. In order to finance these purchases, investors sell their shorterterm assets, which results in a decline in the price of short-term assets and an increase in the yield on short-term assets. In other words, if a recession is expected, long-term interest rates will fall and short-term interest rates will rise. Consequently, prior to a recession, the slope of the term structure of interest rates will become flat (or even inverted), which means that the yield spread declines. Similarly, long-term interest rates rise while shortterm interest rates fall when an expansion is expected, so that an upward-sloping yield curve predicts an expansion. 
The second explanation is based on the expectations hypothesis of the term structure of interest rates. This hypothesis is based on the assumption that similar financial instruments with different maturities are perfect substitutes, so that an investor will be indifferent between investing in one long-term instrument or several similar consecutive short-term instruments, as long as their expected returns are equal (Mishkin, 1998: p. 156). This means that for similar financial instruments the long-term yield will be the average of current and future short-term yields. Assume that a central bank tightens monetary policy by raising short-term rates. Economic agents will view this as a temporary shock and therefore they expect future short-term rates to rise by less than the current change in short-term interest rates. On the basis of the expectations hypothesis of the term structure, long-term rates will rise by less than the current short-term rate. This will lead to a flatter or even an inverted yield curve. Since monetary policy affects economic activity with a lag of 1-2 years, the tightening of policy will cause a reduction of future economic activity and an increase in the probability of a recession. Therefore, prior to a recession (expansion), the yield spread will decline (increase).

The usefulness of the yield spread as business cycle predictor has been confirmed in empirical studies. Estrella and Hardouvelis (1991) were the first to empirically analyse the term structure as a predictor of real economic activity. In their study, regressions of future GNP growth on the slope of the yield curve showed that a steeper (flatter) slope implies faster (slower) future growth in real output. In addition, they also used a probit model, which showed that an increase in the spread between the long- and short-term interest rates implies a decrease in the probability of a recession four quarters later.

In addition to the domestic term structure, Bernard and Gerlach (1996) also tested the ability of foreign term structures to predict business cycle turning points in eight

industrial countries. Using probit models, they showed that the domestic term spreads are statistically significant in explaining business cycle turning points in all eight countries. The period over which the domestic term spread successfully forecasts the turning points varies across countries, but the optimal forecast period ranges from two to five quarters.

Estrella and Mishkin (1998) compared the performance of various financial variables, including four term structures of interest rates, stock prices, monetary aggregates, indexes of leading indicators and other economic variables such as GDP, CPI and exchange rates, as predictors of US recessions. They estimated probit models and showed that the yield curve outperforms other indicators for forecasting beyond one quarter ahead.

The only study on the relationship between the term structure of interest rates and the business cycle in the South Africa economy was done by Nel (1996). Unlike other studies, he analysed the contemporaneous relationship using cointegration techniques, instead of the lead-lag relationship dictated by theory. He showed that quarterly real GDP is a positive function of the yield spread between 10-year government bonds and the 3-month banker's acceptance rate. He found real GDP and the yield spread to be cointegrated and showed that the yield spread is statistically significant in explaining GDP, despite a poor overall fit. 


\section{The Markov switching regime technique}

Assume that there are two regimes, represented by an unobservable process denoted as $S_{t}$. Let $S_{t}$ take on the values 0 and 1 , depending on the prevailing regime. In this case the DGP of the series being modelled, $Y_{t}$, will be different in each regime, for example,

$Y_{t}=\phi_{0,0}+\phi_{1,0} Y_{t-1}+\cdots+\phi_{p, 0} Y_{t-p}+\varepsilon_{t, 0}$ if $S_{t}=0$

$Y_{t}=\phi_{0,1}+\phi_{1,1} Y_{t-1}+\cdots+\phi_{p, 1} Y_{t-p}+\varepsilon_{t, 1} \quad$ if $S_{t}=1$

where $\varepsilon_{t, j} \sim N\left(0, \sigma_{j}^{2}\right)$.

Following Hamilton (1989), assume that $S_{t}$ is a first-order Markov-process, which means that the current regime $\left(S_{t}\right)$ depends only on the regime in the preceding period $\left(S_{t-1}\right)$. This model is completed by defining the transition probabilities of moving from one regime to another (referred to as 'the transition probabilities'):

$P\left(S_{t}=j \mid S_{t-1}=i\right)=p_{i j} \quad i, j=0,1$.

Notice that, since $p_{01}=1-p_{00}$ and $p_{10}=1-p_{11}$, the transition probabilities are completely defined by $p_{00}$ and $p_{11}$.

This version of the model, where the transition probabilities are time-invariant, is called the fixed transition probabilities model. The drawback of this model is that it implies that the expected durations of expansions and recessions can differ, but are forced to be constant over time. Intuitively, the expected duration of an expansion or contraction is generally thought to vary with the underlying strength of the economy. For example, as the economy exits a relatively deep recession and enters a relatively robust recovery period, it is less likely to fall back into the recession (Filardo and Gordon, 1998). The assumption that the transition probabilities are time-invariant, may be costly from an empirical point of view. With fixed transition probabilities, the conditional expected durations do not vary over the cycle. This implies that exogenous shocks, macroeconomic policies and an economy's own internal propagation mechanisms do not affect the expectation of how long an expansion or recession will last (Filardo and Gordon, 1998).

A solution to this problem is to incorporate time-varying transition probabilities (TVTP) into the model, by using a specification for the transition probabilities that reflects information about where the economy is heading. The variations in the transition probabilities will generate variations in the expected durations (Filardo and Gordon, 1998). In contrast with the time-invariant transition probabilities in Eq. (3), the TVTP are 
$P\left(S_{t}=s_{t} \mid S_{t-1}=s_{t-1}, z_{t}\right)=\left[\begin{array}{ll}p_{00}\left(z_{t}\right) & 1-p_{11}\left(z_{t}\right) \\ 1-p_{00}\left(z_{t}\right) p_{11}\left(z_{t}\right)\end{array}\right]$

where $z_{t}$ is the information variable(s) upon which the evolution of the unobserved regime will depend. Examples of information variables are the index of leading indicators, or individual leading indicators such as the term structure of interest rates.

A popular way to model TVTP is to incorporate a simple probit or logit function (see e.g. Filardo and Gordon (1998), Durland and McCurdy (1994) and Bodman (1998)). A probit or logit function can be estimated to measure the transition probability matrix at each period. In this way, the transition probabilities are a function of an economic indicator(s) such as the index of leading indicators (see e.g. Filardo and Gordon (1998)), or an individual leading indicator such as the term structure of interest rates (see e.g. Filardo (1994)). In particular, if a logit function is used the transition probabilities are

$p_{11}=P\left(S_{t}=1 \mid S_{t-1}=1\right)=\exp \left(\alpha_{1}+\beta_{1} z_{t}\right) /\left(1+\exp \left(\alpha_{1}+\beta_{1} z_{t}\right)\right)$

$p_{22}=P\left(S_{t}=2 \mid S_{t-1}=2\right)=\exp \left(\alpha_{2}+\beta_{2} z_{t}\right) /\left(1+\exp \left(\alpha_{2}+\beta_{2} z_{t}\right)\right)$.

The expected duration of a pl $S_{t-1} \mathrm{~s}$ determined by the transition probabilities. This means that variations in $z_{t}$ and will affect the expectation of how long a phase will last.

\section{Literature review}

Business cycles have been modelled using different techniques, such as autoregressive integrated moving average models (e.g. Nelson and Plosser (1982), Beveridge and Nelson (1981) and Campbell and Mankiw (1987)); cointegration techniques (e.g. King et al. (1991)); and the Kalman filter, whereby real GNP is modelled as the sum of unobserved components (e.g. Harvey (1985), Watson (1986) and Clark (1987)). These techniques share a potential shortcoming, namely the assumption that the growth rate of real GNP is a linear stationary process. Linear models are incompatible with the asymmetry between expansions and contractions that has been documented by, amongst others, Neftci (1984), Stock (1987), Diebold and Rudebusch (1990) and Sichel (1993).

Hamilton (1989) proposed a MS model that models real GNP growth as an AR(4) model, allowing for non-linearity by introducing discrete shifts in the mean between highgrowth and low-growth regimes. These discrete shifts have their own dynamics, specified as a two-regime first-order Markov process. The most attractive feature of this model is that no prior information regarding the dates of the two growth periods or the size of the two growth rates is required. In addition, the low-growth rate need not be negative. In this section, a brief overview of the empirical literature on MS models for business cycles and 
on the relationship between the yield spread and the business cycle will be given.

\subsection{Markov models with fixed transition probabilities}

Hamilton (1989) developed a MS model for dating and forecasting business cycles. He applied this model to the quarterly real GNP of the US for the period 1951-1984. In particular, he modelled GNP growth as a AR(4) two-regime MS model. In other words, GNP growth switches between two regimes, which each have a unique intercept, but the AR coefficients are constrained to be the same across regimes. The MS model calculates the probability that the economy is in a particular regime in a certain period. The econometrician then has to devise a dating rule to actually decide from which regime this observation originates. Hamilton used a very popular dating rule, which classifies a particular period as a recession (expansion) if the econometrician concludes that the economy is more likely than not to be in a recession (expansion). That is, when the probability of being in a recession (expansion) is higher than the probability of being in an expansion (recession). The dates of the turning points predicted by his MS model are usually within 3 months of the dates of the official dates set by the National Bureau for Economic Research (NBER).

Goodwin (1993) used Hamilton's (1989) MS model to model the business cycles of eight developed countries. He also used a two-regime AR(4) MS model. The filtered and smoothed conditional probabilities indicated business cycle turning points that closely correlated with official turning points. In addition, he tested whether contractions have shorter durations than expansions, by comparing the expected durations of expansion and recessions. ${ }^{1}$ He rejected the hypothesis of symmetry, in other words, that the expected duration of expansions and recessions are equal.

Ivanova et al. (2000) used the same technique as Hamilton (1989) and Goodwin (1993), but instead of modelling GNP directly, the model used a leading indicator and then considered a change in regime as a business cycle turning point signal. In particular, they modelled the performance of a number of interest rate spreads as predictors of the German business cycle. They used a two-regime, first-order MS model and defined a regime change as the event that the probability of a recession (expansion) is greater than the probability of an expansion (recession). Since the interest rate spread is considered to be a leading indicator of the business cycle, the change in regime is the business cycle turning point signal. Their results indicated that market spreads lead business cycle regimes. None of the bank spreads gave any false signals, but the spreads between government and bank bonds of $1-2$ years gave multiple false signals. The call-rate spread performed slightly less effective than the other spreads, since its predictions lagged the predictions of the other spreads.

\footnotetext{
${ }^{1}$ Implicit in much of the research on business cycles going back to Keynes and before is the notion that business cycles can be characterized as exhibiting sharp drops during contractions followed by gradual movements during expansions.
} 
Instead of a univariate MS model, Kontolemis (1999) used a vector-MS model to date and forecast the US business cycle. In other words, he forced the different indicators to have simultaneous turning points. The four series used in the construction of the coincident index are the index of industrial production, non-agricultural employment, personal income and manufacturing and trade sales. Following Hamilton (1989), the rule for dating the business cycle is based on whether the economy is more likely than not to stay in one of the two phases. In order to eliminate spurious cycles in the monthly series, he imposed a requirement that each cycle be at least 6 months (i.e. two quarters). The estimated probabilities tracked the NBER downturns relatively well. The vector-MS model produced more accurate forecasts than a simple univariate MS model specification.

\subsection{Markov models with time-varying transition probabilities}

Filardo (1994) expanded the MS model to allow for TVTP. He used a logit function to generate the transition probabilities. He compared different information variables, namely the composite index of leading indicators, the interest rate spread, the S\&P stock index and the short-term interest rate. In Filardo's study there is statistically significant evidence that the model supports the two-phase view of the US business cycle. The various leading indicators used, contained different information and gave varying turning points. His results showed that the business cycle dynamics of this model stem mainly from the variation in the transition probabilities, rather than from a shift in the means of the series between regimes.

Instead of using a leading indicator, Durland and McCurdy (1994) allowed the transition probabilities to be duration-dependent, so that the probability of staying in a recession, for example, declines the longer the economy is in a recession. They were able to reject the linear model in favour of a duration-dependent parameterisation of the regime transition probabilities in a regime-switching model. Filardo and Gordon (1998) illustrated that the TVTP can also be modelled with a probit function instead of a logit function. 
Table 1

Cycle phases according to SARB since 1978

\begin{tabular}{llll}
\hline Upward phase & & Downward phase & \\
\hline January 1978 & August 1981 & September 1981 & March 1983 \\
April 1983 & June 1984 & July 1984 & March 1986 \\
April 1986 & February 1989 & March 1989 & May 1993 \\
June 1993 & November 1996 & December 1996 & August 1999 \\
\hline
\end{tabular}

Probit and logit functions are flexible and have a sensible economic interpretation. However, some studies have reported estimation problems when these functions are applied. Simpson et al. (2001) tried to model the TVTP with an exponential function instead of the popular probit or logit functions. The problem with the logistic form is that the interpretation is not as economically intuitive as the logit or probit form and it may not lead to sensible probabilities for certain values of the leading indicator because of its shape. Their results indicate that a constant transition probability MS model captures the major recessions of the sample, but the use of leading indicators through the TVTP framework improves this regime's recognition.

Layton and Katsuura (2001) compared different techniques to the MS model in dating and forecasting US business cycles. They estimated binomial and multinomial probit models, binomial and multinomial logit models and a two-regime MS model in which the transition probabilities are modelled as logistic functions. Their results showed that the MS model performed relatively better than the other models. The MS model overcomes a very real practical and fundamental limitation of the logit and probit specifications as far as their use in real time business cycle phase shift forecasting is concerned. Their estimation requires exact knowledge of the regime of the economy for every observation in the estimation period so as to assign values to the dependent variable in the model.

\section{Empirical analysis}

In this paper, the South African business cycle will be modelled with linear and nonlinear models using quarterly data for the period 1978-2001. The official business cycle dates of the South African Reserve Bank are presented in Table 1.

\subsection{The linear model}

Following the most popular MS regime specification for business cycles, real GDP growth is modelled as an $\mathrm{AR}(4)$ process with different intercepts in the two different regimes (see e.g. Hamilton (1989), Durland and McCurdy (1994), Goodwin (1993) and Bodman (1998)). Therefore, in the linear model real GDP growth $\left(Y_{t}\right)$ will be modelled as an AR(4) process (Table 2). The performance of this model is evaluated in Section 6, where it is also compared with the performance of the MS model. 
Table 2

Autoregressive model

\begin{tabular}{lrlrc}
\hline Dependent variable: $Y_{t}$ & & & \\
\hline Variable & Coefficient & S.E. & \multicolumn{1}{l}{$t$-Statistic } & Probability \\
\hline$Y_{t-1}$ & 0.421611 & 0.108621 & 3.881486 & 0.0002 \\
$Y_{t-2}$ & 0.080301 & 0.118026 & 0.680367 & 0.4981 \\
$Y_{t-3}$ & -0.021405 & 0.117935 & -0.181498 & 0.8564 \\
$Y_{t-4}$ & -0.043410 & 0.107054 & -0.405500 & 0.6861 \\
$C$ & 1.136723 & 0.445845 & 2.549594 & 0.0125 \\
$R^{2}$ & 0.208481 & Akaike criterion & 5.342205 & \\
Adjusted $R^{2}$ & 0.172090 & Schwarz criterion & 5.479258 & \\
$F$-statistic & 5.728825 & Prob $(F$-statistic $)$ & 0.000386 & \\
\hline
\end{tabular}

\subsection{Logit model}

The results in Table 3 indicate that the probability of a recession in a specific quarter is a negative function of the yield spread lagged two quarters. Expressed algebraically,

$P\left(R_{t+2}=1\right)=F\left(0.514-0.995 x_{t}\right)$

where $F$ is the cumulative logistic distribution, $x_{t}$ is the yield spread in period $t$ and $R_{t}$ is a dummy variable that takes on the value one if the economy is in a recession in period 1 and 0 otherwise. In other words, an increase in the spread between the long-term and short-term interest rates implies a decrease in the probability of a recession two quarters later. According to the results in Table 3, the relationship between the probability of a recession and the yield spread is statistically significant. Fig. 1 plots the estimated probability of a recession constructed with Eq. (7). The shaded areas denote periods of actual recessions as classified by the South African Reserve Bank.

Table 3

Logit model

\begin{tabular}{lrlrl}
\hline Dependent variable: Rec $_{t}{ }^{\mathrm{a}}$ & & & \\
\hline Variable & Coefficient & S.E. & z-Statistic & Probability \\
\hline Spread $_{t-2}$ & -0.994626 & 0.204696 & -4.859029 & 0.0000 \\
C & 0.514365 & 0.348941 & 1.474072 & 0.1405 \\
S.E. of regression & 0.299932 & Akaike criterion & 0.671411 & \\
SSR & 8.096318 & Schwarz criterion & 0.726232 & \\
\hline
\end{tabular}

${ }^{a} \operatorname{Rec}_{t}$ is a dummy variable that takes on the value 1 if the economy is officially in a recession in period $t$ and 0 if not. 


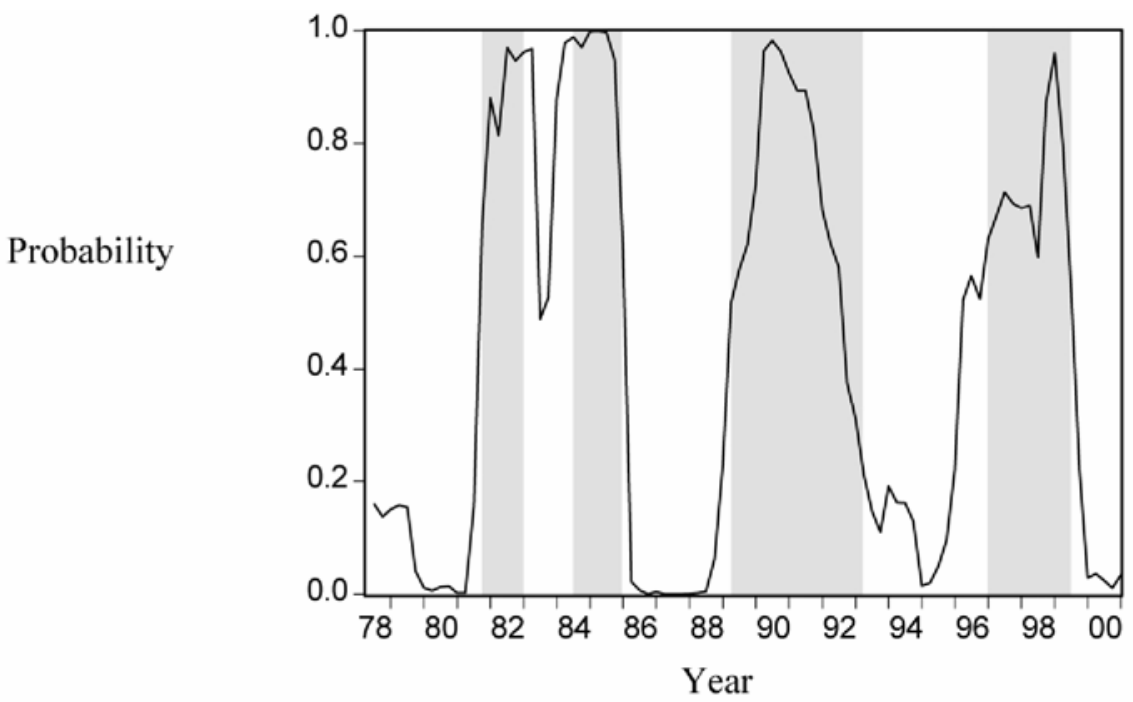

Fig. 1. Regression probabilities of logit model.

\subsection{The Markov switching regime model}

A first-order, two-regime MS model was estimated for the South African business cycle. The model was specified as follows

$Y_{t}=\mu_{2}\left(1-S_{t}\right)+\mu_{1} S_{t}+\phi_{1}\left(Y_{t-1}-\left(\mu_{2}\left(1-S_{t-1}\right)+\mu_{1} S_{t-1}\right)\right)+\phi_{2}\left(Y_{t-2}-\left(\mu_{2}\left(1-S_{t-2}\right)+\mu_{1} S_{t-2}\right)\right)$

$+\phi_{3}\left(Y_{t-3}-\left(\mu_{2}\left(1-S_{t-3}\right)+\mu_{1} S_{t-3}\right)\right)+\phi_{4}\left(Y_{t-4}-\left(\mu_{2}\left(1-S_{t-4}\right)+\mu_{1} S_{t-4}\right)\right)+\varepsilon_{t}$

where

$\varepsilon_{t} \sim N\left(0, \sigma^{2}\right)$

$S_{t}=1$ if low-growth regime, 0 otherwise

$P\left(s_{t}=j \mid s_{t-1}=i\right)=p_{i j, t} \quad i, j=0,1$.

Following Filardo (1994) and Durland and McCurdy (1994), amongst others, the transition probabilities were modelled with a logit function:

$p_{11, t}=p\left(S_{t}=1 \mid S_{t-1}=1\right)=\exp \left(\alpha_{1}+\beta_{1} z_{t-k}\right) /\left(1+\exp \left(\alpha_{1}+\beta_{1} z_{t-k}\right)\right)$ 
Table 4

Parameters of growth equation in Markov model

$$
\begin{aligned}
& \text { Growth model: } \\
& \begin{aligned}
Y_{t}= & \mu_{2}\left(1-S_{t}\right)+\mu_{1} S_{t}+\phi_{1}\left(Y_{t-1}-\left(\mu_{2}\left(1-S_{t-1}\right)+\mu_{1} S_{t-1}\right)\right)+\phi_{2}\left(Y_{t-2}-\left(\mu_{2}\left(1-S_{t-2}\right)+\mu_{1} S_{t-2}\right)\right) \\
& +\phi_{3}\left(Y_{t-3}-\left(\mu_{2}\left(1-S_{t-3}\right)+\mu_{1} S_{t-3}\right)\right)+\phi_{4}\left(Y_{t-4}-\left(\mu_{2}\left(1-S_{t-4}\right)+\mu_{1} S_{t-4}\right)\right)+\varepsilon_{t}
\end{aligned}
\end{aligned}
$$

\begin{tabular}{lrr}
\hline Parameter & Coefficient & S.E. \\
\hline$\mu_{1}$ & -1.061275 & 0.287213 \\
$\mu_{2}$ & 3.741749 & 0.313490 \\
$\phi_{1}$ & 0.332210 & 0.064285 \\
$\phi_{2}$ & 0.035363 & 0.067236 \\
$\phi_{3}$ & -0.032597 & 0.068706 \\
$\phi_{4}$ & 0.001868 & 0.067109 \\
$\sigma^{2}$ & 2.693322 & 0.293941 \\
\hline
\end{tabular}

$p_{00, t}=p\left(S_{t}=0 \mid S_{t-1}=0\right)=\exp \left(\alpha_{0}+\beta_{0} z_{t-k}\right) /\left(1+\exp \left(\alpha_{0}+\beta_{0} z_{t-k}\right)\right)$

where the yield spread was used as the information variable, $z_{t}$, and the coefficients $\alpha$ and $\beta$ were estimated with maximum likelihood.

Table 4 presents significant evidence to support the assumption that two distinct growth-rate phases characterize the business cycle. The point estimates of the regimedependent means, $\mu_{1}$ and $\mu_{2}$, are statistically different. The mean growth rate in the high-growth regime, $\mu_{2}$, is significantly positive, while the mean growth rate in the low-growth regime, $\mu_{1}$, is significantly positive. Because the sample dichotomises into phases that exhibit declining aggregate output and growing aggregate output, each can be labelled as low-growth and high-growth regimes of the economy.

According to the results in Table 5, all the estimated coefficients in the data generation process of the transition probabilities are significant. The parameters, which govern the time-variation of the transition probabilities, namely $\beta_{1}$ and $\beta_{2}$, have opposite signs. This is consistent with the intuition that an increase in the yield spread decreases the probability of remaining in an expansion and decreases the probability of remaining in a recession. The parameters $\alpha_{0}$ and $\alpha_{1}$ determine the unconditional mean duration of recessions and expansions.

Fig. 2 plots the inferred probability of a low-growth-rate regime given the available data. When above (below) 0.5, the economy is more likely to be in a recession (expansion). The turning points predicted by the Markov model are highly correlated with the dates of the official turning points and the regime probabilities are generally very close to 0 or 1 , so these turning points explicitly indicate one of the regimes. The Markov model gives 'false' signals of an expansion in 1985 and a recession in 1994, but both these signals only last for one quarter and can therefore be eliminated by applying the common dating rule that a cycle should last for at 
Table 5

Parameters of transition probability equation in Markov model

TVTP model:

$p_{i i, t}=p\left(S_{t}=i \mid S_{t-1}=i\right)=\exp \left(\alpha_{i}+\beta_{i} z_{t-k}\right) /\left(1+\exp \left(\alpha_{i}+\beta_{i} z_{t-k}\right)\right)$

\begin{tabular}{lrl}
\hline Parameter & Coefficient & S.E. \\
\hline$\alpha_{1}$ & -0.880836 & 0.567530 \\
$\beta_{1}$ & -0.784035 & 0.418566 \\
$\alpha_{2}$ & 1.250595 & 0.555241 \\
$\beta_{2}$ & 0.388441 & 0.184527 \\
\hline
\end{tabular}

least two quarters. However, instead of regarding these signals as 'false' simply because they do not correspond to the official dates, a careful analysis of the periods during which they occurred show that they were not truly false in the sense of incorrectly indicating the general state of the economy.

According to the definition used by the Reserve Bank, the economy has to have at least two consecutive quarters of negative economic growth before it is classified as being in a recession. In other words, if only a single quarter of negative growth is experienced it will not be considered an official recession. For example, during the first quarter of 1994, the economy contracted by $0.6 \%$, but since the previous

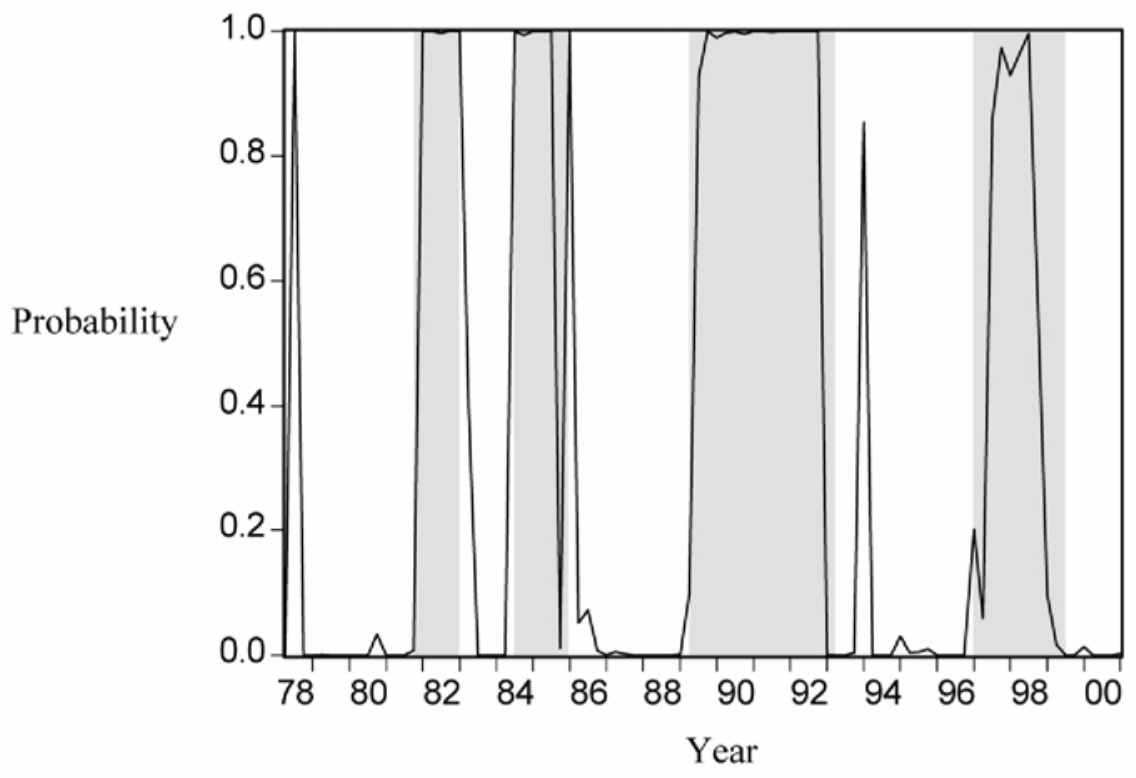

Fig. 2. Markov model: TVTP. 
Table 6

Model selection criteria for linear and MS models

\begin{tabular}{lll}
\hline Criteria & Linear model & MS model \\
\hline MAPE & 1.13 & 1.48 \\
RMSE & 3.31 & 2.99 \\
MAE & 2.46 & 2.20 \\
Theil's $U$ & 0.48 & 0.36 \\
\hline
\end{tabular}

and following quarters both had positive economic growth this was not defined as a recession. The high recession probability in the first quarter of 1994 is therefore reflecting this drop in economic growth rather than giving a false signal. Likewise, the low recession probability in the last quarter of 1985 corresponds to a positive economic growth rate, but since growth was negative during the following quarter the economy was officially still in a recession. This was also the case with the third quarter of 1978 . This means that the differences between the Markov model and the official classification should not be viewed as 'false' signals, but should rather be viewed as additional information given by the Markov model regarding the true state of the economy which is not influenced by an asymmetric classification definition.

\section{Model selection}

In this section, the results of the MS model will be compared with two alternative types of models. The MS model's accuracy in modelling economic growth will be compared with the linear model, while the model's accuracy in predicting business cycle turning points will be compared with the turning points predicted by a logit model.

\subsection{Comparing the linear and Markov models}

The mean absolute percentage error (MAPE), the square root of the mean squared error (RMSE), the mean absolute error (MAE) and Theil's inequality coefficient (U) were used to compare the linear and MS models. The Markov model was preferred to the AR(4) model based on the chosen criteria (Table 6).

\subsection{Comparing the logit and Markov models}

i. Number of wrong predictions: $\sum_{i=1}^{n}\left(y_{i}-\hat{y}_{i}\right)^{2}$

ii. Sum of squared residuals (SSR): $\sum_{i=1}^{n}\left(y_{i}-F\left(x_{i}^{\prime} \hat{\beta}\right)\right)^{2}$

iii. Sum of absolute value of residuals: $\sum_{i=1}^{n}\left|y_{i}-F\left(x_{i}^{\prime} \hat{\beta}\right)\right|$ 
Table 7

Model Selection Criteria for Logit and MS models

\begin{tabular}{lcc}
\hline Criteria & MS model & Logit model \\
\hline Number of wrong predictions & 12 & $\mathbf{1 1}$ \\
Sum of squared errors & 9.58 & $\mathbf{8 . 0 3}$ \\
Efron's $R^{2}$ & $\mathbf{0 . 5 7}$ & 0.50 \\
Sum of absolute errors & $\mathbf{1 4 . 5 8}$ & 16.67 \\
\hline
\end{tabular}

iv. Efron's $R^{2}: R_{\mathrm{Efron}}^{2}=\frac{\sum\left(y_{i}-F\left(x_{i}^{\prime} \beta\right)\right)^{2}}{\sum\left(y_{i}-\hat{y}_{i}\right)^{2}}$

where $\hat{y}_{i}=1$ if $F\left(x_{i}^{\prime} \hat{\beta}\right) \geqslant 0.5$ and $\hat{y}_{i}=0$ if $F\left(x_{i}^{\prime} \hat{\beta}\right)<0.5$.

The model selection criteria for the logit and Markov models are given in Table 7. The preferred model according to each criterion is indicated in bold print. The results in Table 7 indicate that the Markov model made fewer wrong predictions than the logit model with regards to the inferred regime of the economy. However, this criterion penalizes a model only for the number of times that it is wrong, without taking into account the size of the mistaken probability. According to the sum of squared errors, the logit model is preferred to the Markov model. However, since the errors will always lie between 0 and 1 , the larger the error, the smaller its square will be. When the sum of the absolute values of the errors is used instead, the Markov model is preferred to the logit model.

It should be kept in mind that the logit model is designed to attempt to obtain the best fit for the official turning points. The Markov model, on the other hand, does not use the official turning points in its estimation at all. Against this background, the Markov model actually compares favourably with the logit model and makes the least mistakes.

\section{Conclusion}

In this paper, the South African business cycle has been modelled with a two-state first-order MS regime with TVTP, using the logit technique and an autoregressive model. The transition probabilities and the logit model were estimated with the yield spread as explanatory variables. The results indicated that two distinct growth rate phases, these being low and high growth rate phases, characterize the business cycle.

One of the most important issues for macroeconomic policy makers when making decisions about stabilization policies is to predict the most likely time of the next business cycle turning point. Both the MS and the logit models accurately predicted the historical turning points of the South African business cycle. This finding has important policy implications, since the yield spread was used to generate the time-varying probabilities of the MS model as well as the recession probabilities of the logit model. In other words, a strong relationship exists between interest rates and the business cycle, where interest rates lead the business cycle. This implies that monetary authorities can 
significantly influence the course of the business cycle since they can directly influence interest rates. In addition, accurate predictions regarding the phase of the business cycle, in other words whether the economy is in a recession or not, can be made 6 months ahead based solely on the yield spread.

\section{References}

Bernard, H., Gerlach, S., 1996. Does the term structure predict recession? The international evidence. Working Paper No. 37. Bank for International Settlements, Basle.

Beveridge, S., Nelson, C., 1981. A new approach to decompositions of economic time series into permanent and transitory components with particular attention to measurement of the business cycle. J. Monetary Econ. 22, 71-80.

Bodman, P.M., 1998. Asymmetry and duration dependence in Australian GDP and unemployment. Econ. Record 74 (227), 399-411.

Campbell, J.Y., Mankiw, N.G., 1987. Are output fluctuations transitory? Quart. J. Econ. 102, 857-880.

Clark, P.K., 1987. The cyclical component of US economic activity. Quart. J. Econ. 102, 857-880.

Diebold, F., Rudebusch, G., 1990. A nonparametric investigation of duration dependence in the American business cycle. J. Polit. Econ. 98, 596-616.

Durland, J.M., McCurdy, T.H., 1994. Duration-dependent transitions in a Markov model of US GNP growth. J. Bus. Econ. Stat. 12 (3), 279-288.

Estrella, A., Hardouvelis, G.A., 1991. The term structure as a predictor of real economic activity. J. Finance 46, 555-575.

Estrella, A., Mishkin, F.S., 1998. Predicting US recessions: financial variables as leading indicators. Rev. Econ. Stat. 80, 45-60.

Filardo, A.J., 1994. Business-cycle phases and their transitional dynamics. J. Bus. Econ. Stat. 12 (3), 299-308.

Filardo, A.J., Gordon, S.F., 1998. Business cycle durations. J. Economet. 85 (1), 99-123.

Goodwin, T.H., 1993. Business cycle analysis with a Markov-switching model. J. Bus. Econ. Stat. 11 (3), 331-339

Hamilton, J.D., 1989. A new approach to the economic analysis of nonstationary time series and the business cycle. Econometrica 57, 357-384.

Harvey, A.C., 1985. Trends and cycles in macroeconomic time series. J. Bus. Econ. Stat. 3, 216-227.

Ivanova, D., Lahiri, K., Seitz, F, 2000. Interest rate spreads as predictors of German inflation and business cycles. Int. J. Forecasting 16, 39-58.

King, R.G., Plosser, C.I., Stock, J.H., Watson, M.W., 1991. Stochastic trends and economic fluctuations. Am. Econ. Rev. 81, 819-840.

Kontolemis, Z.G., 1999. Analysis of the US Business Cycle with a vector-Markov-switching model. International Monetary Fund Working Paper: WP/99/107.

Layton, A.P., Katsuura, M., 2001. Comparison of regime switching, probit and logit models in dating and forecasting US business cycles. Int. J. Forecasting 17 (3), 403-417.

Mishkin, F.S., 1998. The Economics of Money, Banking and Financial Markets. Addison-Wesley.

Neftci, S., 1984. Are economics time series asymmetric over the business cycle? J. Polit. Econ. 92, 307-328.

Nel, H., 1996. The term structure of interest rates and economic activity in South Africa. S. Afr. J. Econ. 64 (3), 161-174.

Nelson, E., Plosser, C., 1982. Trends and random walks in macroeconomic time series. J. Monetary Econ. 10, 139-162.

Sichel, D., 1993. Business cycle asymmetry: a deeper look. Econ. Inq. 31, 224-236.

Simpson, P.W., Osborn, D.R., Sensier, M., 2001. Modelling business cycle movements in the UK economy. Economica 69, 243-267. 
Stock, J., 1987. Measuring business cycle time. J. Polit. Econ. 95, 1240-1261.

Terasvirta, T., Anderson, H.M., 1992. Characterizing nonlinearities in business cycles using smooth transition autoregressive models. J. Appl. Econom. 7, S119-S136.

Watson, M.W., 1986. Univariate detrending methods with stochastic trends. J. Monetary Econ. 18, 49-76. 